\title{
Epidermal growth factor, latrophilin, and seven transmembrane domain-containing protein I marker, a novel angiogenesis marker
}

REVIEW

This article was published in the following Dove Press journal:

OncoTargets and Therapy

16 December 2015

Number of times this article has been viewed

\section{Florentina Serban \\ Stefan-Alexandru Artene \\ Ada Maria Georgescu \\ Stefana Oana Purcaru \\ Daniela Elise Tache \\ Oana Alexandru \\ Anica Dricu}

Department of Biochemistry, University of Medicine and Pharmacy of Craiova, Craiova, Romania
Correspondence: Anica Dricu Department of Biochemistry, University of Medicine and Pharmacy of Craiova, Petru Rares 2, 200349, Craiova, Romania Email anica.dricu@live.co.uk

\begin{abstract}
Epidermal growth factor, latrophilin, and seven transmembrane domain-containing protein 1 on chromosome 1 (ELTD1), an orphan adhesion G-protein coupled receptor, was reported as a regulator of angiogenesis, also involved in cancer progression and development. More recently, ELTD1 was identified as a potential new tumor marker for high-grade glioma. ELTD1, belongs to the G-protein coupled receptor superfamily that comprises the biggest receptor family in the human genome. Following the discovery of ELTD1 almost a decade ago, only a few research groups have attempted to find its role in normal and tumor cells, important information about this receptor remaining still unknown. The ELTD1 ligand has not currently been identified and intracellular signaling studies have not yet been performed in normal or tumor cells. Although the current published data on ELTD1 function and structure are rather limited, this receptor seems to be very important, not only as biomarker, but also as molecular target in glioblastoma. This review summarizes and discusses the current knowledge on ELTD1 structure, function, and its role in both physiological and tumoral angiogenesis.
\end{abstract}

Keywords: ELTD1, angiogenesis, glioma, biomarker

\section{Introduction}

Since the early ages of oncology, medical researchers have strived to discover new biomarkers, which can be correlated with early stages of cancer development, tumor progression, and resistance to therapy. With the discovery of targeted therapy, some of these markers became interesting therapeutic targets due to their implication in intricate pathophysiological processes involved in cancer growth, invasion, or resistance to curative approaches. One of the most studied pathophysiological events involved in cancer development and progression is angiogenesis. Depriving nascent cancer cells of their nutrients provided by aberrant, newly formed blood vessels became an attractive approach that, in theory, could deter or even reverse neoplastic growth. However, both early and more recent trials have yielded limited results due to the complex nature of microvasculature in each cancer type, the multiple pathways implicated in cell signaling, and the vast number of genes responsible for both normal and cancer angiogenesis. ${ }^{1-5}$ Together, these variables can confer both natural and acquired resistance to anti-angiogenic therapy, leading to mixed clinical results. ${ }^{6-8}$ Many angiogenic inhibitors, designated for cancer treatment, are currently in preclinical and clinical use. The vascular endothelial growth factor receptor family is a well-studied angiogenic class of receptors $^{9-11}$ that have been constantly used to develop new cancer therapies for quite a while now. ${ }^{12-14}$ The therapeutic results, however, for many malignant diseases, in which vascular endothelial growth factor receptor dysfunction is believed 
to drive tumor angiogenesis, have been ineffective. Future approaches should include inhibition of multiple pathways involved in cancer microvasculature formation or the discovery of new angiogenesis markers, more specific for each cancer type..$^{15-18}$

One such possible candidate is epidermal growth factor, latrophilin, and seven transmembrane domain-containing protein 1 on chromosome 1 (ELTD1), a biomarker recently linked to both normal and pathological angiogenesis. ${ }^{19,20}$ An editorial article linked ELTD1 levels to how the human organism responds to hematopoietic stem cell transplant by developing graft-versus-host disease. ${ }^{21}$ Using complementary DNA microarray, another study also found that ELTD1 was significantly upregulated in patients with ulcerative colitis with dysplastic lesions when compared with normal, nondysplastic, and colic mucosa. ${ }^{22}$ Upregulation of the ELTD1 gene was observed in studies describing genomic adaption to high altitudes in the Andean population, ${ }^{23}$ cannabis use disorders, ${ }^{24}$ genetic predisposition for obesity in both humans and pigs, ${ }^{25}$ and even resistance to therapy in cattle afflicted by ticks. ${ }^{26}$

Initially mentioned in 2001, as a receptor normally regulated in the human heart, ${ }^{27}$ ELTD1 has been recently linked to the progression and development of glioblastoma multiforme (GBM) ${ }^{28,29}$ a particularly aggressive brain tumor with a very bleak prognosis.

Although it was discovered 14 years ago, ${ }^{27}$ in the scientific literature, only a few published works have dealt directly with this topic. The current review is an analysis of the information currently available on ELTD1.

\section{Origin and structure of the ELTD I receptor}

Ontogenetically, ELTD1 belongs to the G-protein coupled receptor (GPCR) superfamily, which comprises the biggest receptor family in the human genome. Also called the $7 \alpha$-helicases transmembrane receptors, the GPCR superfamily transducts signals from the extracellular to the intracellular domain using guanine-binding proteins. The GPCR superfamily is involved in a multitude of human physiological processes, pertaining to different areas such as chemotaxis, smell, hormone secretion, taste, vision, or inflammation. ${ }^{30-32}$

Containing over 900 members, the GPCR superfamily comprises five major families: glutamate (22 members), rhodopsin (701 members), adhesion (33 members), frizzled (11 members), and secretin (15 members). ${ }^{33}$

The second biggest of the five families forming the GPCR super group, the adhesion family was initially considered as part of the secretin family, but was later revealed to be a distinct group. As a particular feature, this family presents an unusually elongated N-terminal ectodomain, which is often perceived as combinations of different adhesion-linked motifs: cadherins, ${ }^{34}$ thrombospondins, ${ }^{35,36}$ leucine-rich repeats, ${ }^{37}$ and epithelial growth factor (EGF)-like domain. ${ }^{38,39}$ Members of the adhesion family are implicated in multiple cellular functions such as cytoskeletal regulation, ${ }^{40-43}$ planar cell polarity, ${ }^{42,44,45}$ cell adhesion and migration, ${ }^{46-48}$ cellular proliferation and death, ${ }^{35,49,50}$ hematopoiesis, immunity, ${ }^{51-53}$ and angiogenesis. ${ }^{19,54-57}$ The adhesion family includes the latrophilin-like subfamily, with its four members: the orphan ELTD1 receptor, as well as the latrophilin 1, 2, and 3 receptors. ${ }^{58}$

Nechiporuk et $\mathrm{al}^{27}$ mapped the ELTD1 gene on the 1p33-p32 band, belonging to chromosome 1 . The gene contains 15 exons having two splice variants: a full-length version and a shorter variant represented by a fraction of a transmembrane domain. ${ }^{59}$ The gene encodes a 3,527 nucleotide transcript, which further translates into a 690 amino acid protein. The ELTD1 receptor is formed of a large extracellular domain, a seven transmembrane domain coupled with a short cytoplasmic tail. The extracellular domain contains an N-terminal region, an EGF-like domain, a calcium-binding EGF domain, and a GPCR proteolysis site. The cytoplasmic domain contains a tyrosine kinase phosphorylation site, suggested to be involved in receptor intracellular signaling (Figure 1). ${ }^{27}$ Unfortunately, no information is yet available in current literature on the downstream signaling pathways implicated in signal transduction or the ligands that bind to the ELTD1 receptor.

\section{ELTD I implication in angiogenesis}

Due to the low number of studies concerning ELTD1, its roles in both physiological and pathological angiogenesis are quite unknown. In the first study published in this area, Nechiporuk et $\mathrm{al}^{27}$ asserted that the ELTD1 receptor was highly expressed in cardiomyocytes and smooth muscle cells of both blood vessels and bronchi, in murine models. ELTD1 regulation was also linked to the switch between hyperplastic and hypertrophic evolution in the development of cardiomyocytes during the physiological differentiation process, in both human and rat models. The receptor's presence in the coronary arteries also raises further question marks regarding its implication in coronary angiogenesis. ${ }^{27}$ More recently, another study mentioned that ELTD1 was actively implicated in cardiac hypertrophy, in rat models.$^{63}$ This study also pointed out that ELTD1 impairment was linked to the faulty cardiomyocytic remodeling process, produced by 


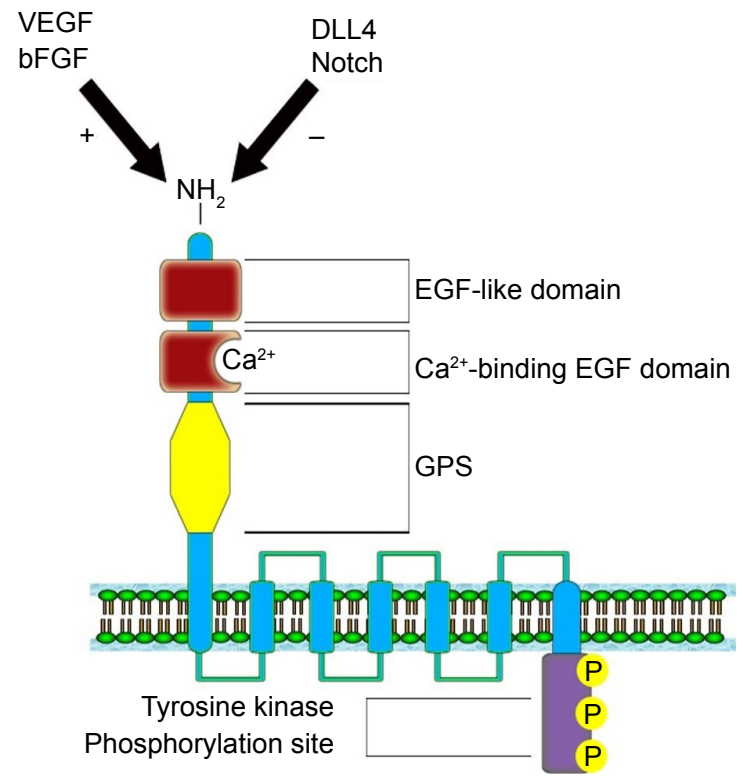

Figure I Structure of the ELTDI receptor. The VEGF/bFGF signaling pathway has a positive effect on ELTDI expression, while DLL4/Notch pathway determines a reduction in protein expression. ${ }^{60-62}$

Abbreviations: ELTDI, epidermal growth factor, latrophilin, and seven transmembrane domain-containing protein I on chromosome I; VEGF, vascular epithelial growth factor; FGF, fibroblast growth factor; DLL4, delta-like ligand 4; GPS, G-protein coupled protein hormone receptor proteolysis site.

cardiac pressure overload. ELTD1 gene knockout resulted in an abrupt rise in myocardial fibrosis and hypertrophy of cardiac myocytes.

ELTD1 was also reported to be involved in brain angiogenesis. A study by Wallgard et $\mathrm{al}^{1}$ of 58 genes involved in the development of microvasculature in different tissues indicated that ELTD1 expression within the endothelial cells of small blood vessels of the cerebrum increased by 254-fold in comparison to other areas of the brain. This ranked ELTD1 first as a potential marker for microvascular development, making it a particularly interesting target for future therapeutic approaches to target angiogenesis. ELTD1 was also found to be expressed in nonpathological samples from tissues, organs, or cell lines belonging to murine models and the results were reported in The Human Protein Atlas and the Biogps Online Database. Although results shown in each dataset vary, the highest levels of ELTD1 gene expression were obtained from the same organs, tissues, and cell lines: lungs, hematopoietic stem cells, common myeloid progenitors, heart, adrenal glands, kidneys, or granulomonocyte progenitors (Figure 2). The relative abundance of ELTD1 in some tissues may prove valuable in the future, unlocking further steps into understanding how angiogenesis differs in different organs. It also hints to a hope that ELTD1 may play a larger role in angiogenesis, not only in the brain, but also in other major organs.

\section{ELTD I roles in cancer}

GBM has long been considered an immense obstacle for modern medicine, being both the most common and the most aggressive brain tumor to date.$^{65}$ Considered a grade IV glioma by the World Health Organization, GBM has an extremely poor prognosis with a vast majority of patients dying within 2 years of diagnosis, with less than $5 \%$ of them surviving more than 3 years. ${ }^{66}$

Therapeutic approaches involving chemotherapy, radiotherapy, targeted therapy, and/or combined regimes have so far yielded very limited results with a poor contribution to GBM patient survival. ${ }^{67}$ So far, no viable biomarker has been selected as a strong candidate among the numerous gene alterations, protein overexpressions/suppressions, and abnormal signaling pathways in glioblastoma. ${ }^{28}$ One of the most well-known markers for GBM is the epithelial growth factor receptor (EGFR). EGFR amplification, along with mutations such as EGFRvIII/AEGFR, has long been considered as poor prognostic markers for GBM patients, but also viable therapeutic targets. ${ }^{68-70}$ Other biomarkers include mutations of the isocitrate dehydrogenase enzyme (IDH) with its two isoforms IDH1 and IDH2, considered the genetic signature for secondary GBMs, ${ }^{71} \mathrm{O}^{6}$-methylguanine DNA methyltransferase protein expression and methylation status, which are considered markers for slower tumor progression, ${ }^{72}$ PTEN gene mutation. ${ }^{73,74}$ Circulating biomarkers such as extracellular vesicles were recently mentioned as valuable biomarkers for GBM. ${ }^{75}$ Extracellular vesicles are membranesurrounded structures, secreted by cells in the biological fluids and consist of a mixture of several proteins, lipids, nucleic acids, glycans, and other biomolecules. These metabolites are suggested to be tumor-specific, thus considered to be good circulating biomarkers for GBM progression and response to the therapy. ${ }^{75}$ In a study by Towner et a ${ }^{29}$ conducted on human and rodent glioma samples, higher levels of ELTD1 were found in high-grade gliomas compared with low-grade gliomas. Higher levels of ELTD1 were also associated with the mesenchymal subtype compared with the proneural subtype. However, the authors didn't find any correlations between ELTD1 levels and survival rates in both the human and murine models. ${ }^{29}$

To analyze things from a broader perspective, an online database has also compared various tumor cell lines to see how ELTD1 levels correlate with different types of cancer (Figure 3). Surprisingly, in contrast with the previous studies we mentioned, the results placed ELTD1 expression in GBM lines midway through the list. More surprisingly, immunohistochemical staining did not find 
A

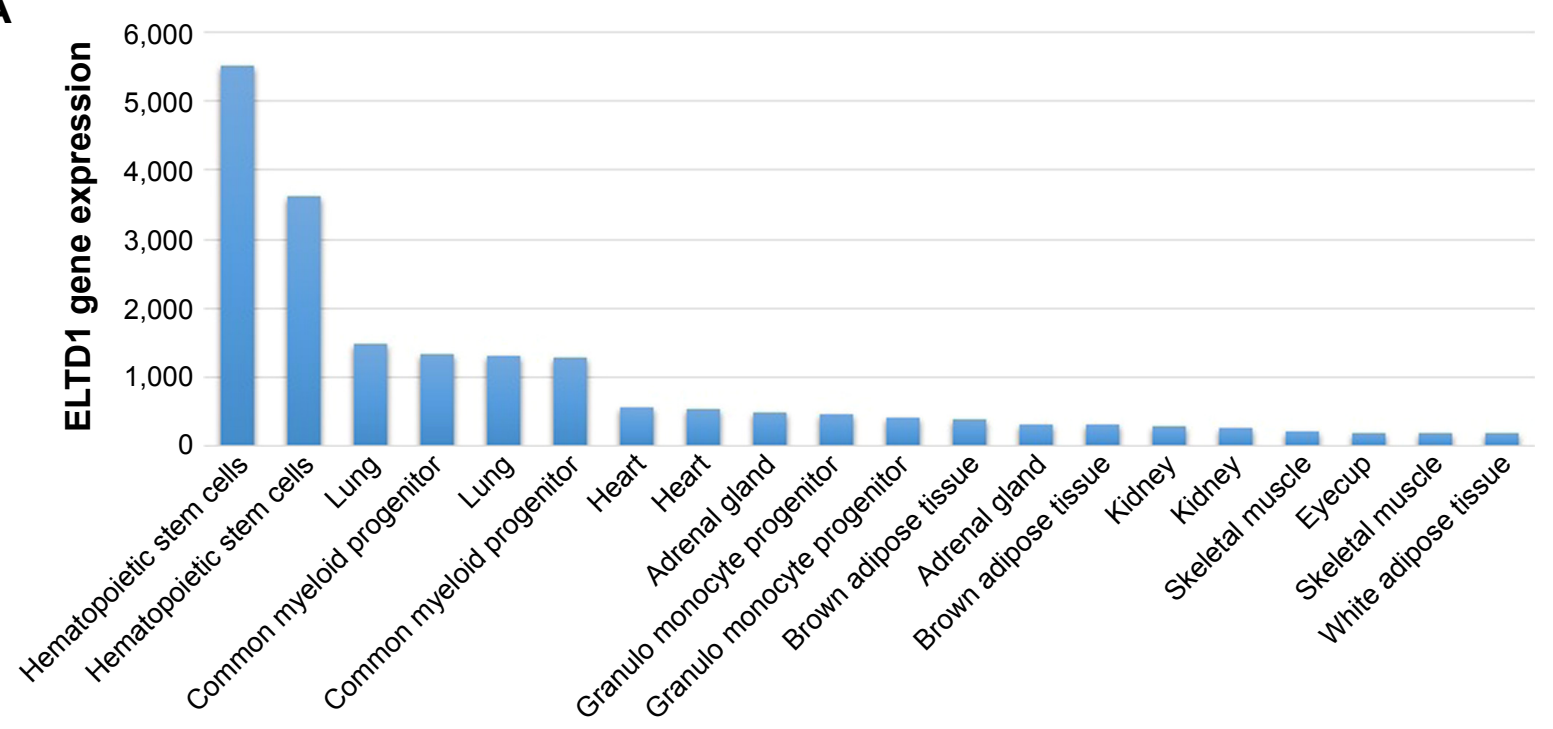

B

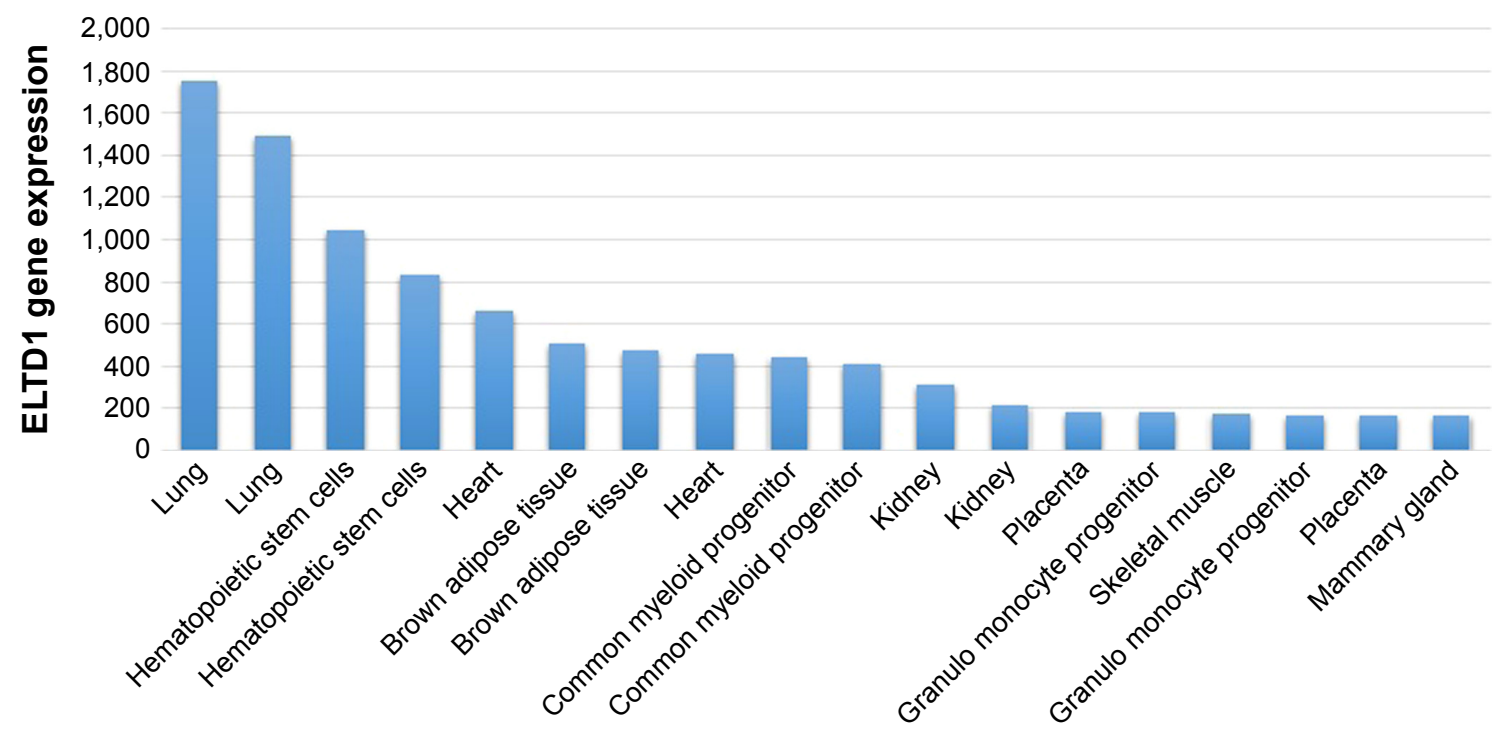

Figure 2 ELTDI gene expression in tissues, organs, or cell lines in the I,418,058 (A) and I,418,059 (B) databases. The samples were obtained from mice. Data were obtained from the Biogps online database (http://biogps.org/\#goto=genereport\&id=170,757, accessed October 17, 2015). ${ }^{64}$ Results are represented as the 20 most highly expressed gene levels for each probe in order to highlight the most relevant data.

Abbreviation: ELTDI, epidermal growth factor, latrophilin, and seven transmembrane domain-containing protein I on chromosome I.

any ELTD1 levels in glioma tumor samples (http://www. proteinatlas.org/ENSG00000162618-ELTD1/cancer, accessed October 17, 2015). However, it should be noted that the database refers only to staining in glioma, without mentioning if the samples were taken from high- or lowgrade gliomas. As Towner et $\mathrm{al}^{29}$ pointed out, higher levels of ELTD1 were associated with the more aggressive, highgrade gliomas in contrast to low-grade ones.

In order to better understand how the receptor works, alterations to the ELTD1 genetic sequence in different cancers were also taken into consideration (Figure 4). By comparison with other cancer types, ELTD1 alterations were almost nonexistent in malignant gliomas. These findings suggest that while a high level of ELTD1 expression may be indicative of the presence or aggressiveness of a malignant glioma, mutation levels are not linked to any aspect of tumor evolution.

ELTD1 has also been implicated in the angiogenesis of other types of cancer. A study of various tumor samples (renal, colorectal, ovarian, and head and neck) showed a match between the upregulation of the gene encoding ELTD1 and tumor development. ${ }^{19}$ Tissues of tumoral origin presented higher levels of protein expression when compared with normal tissue samples, while vascular smooth muscle 
Antibody staining score

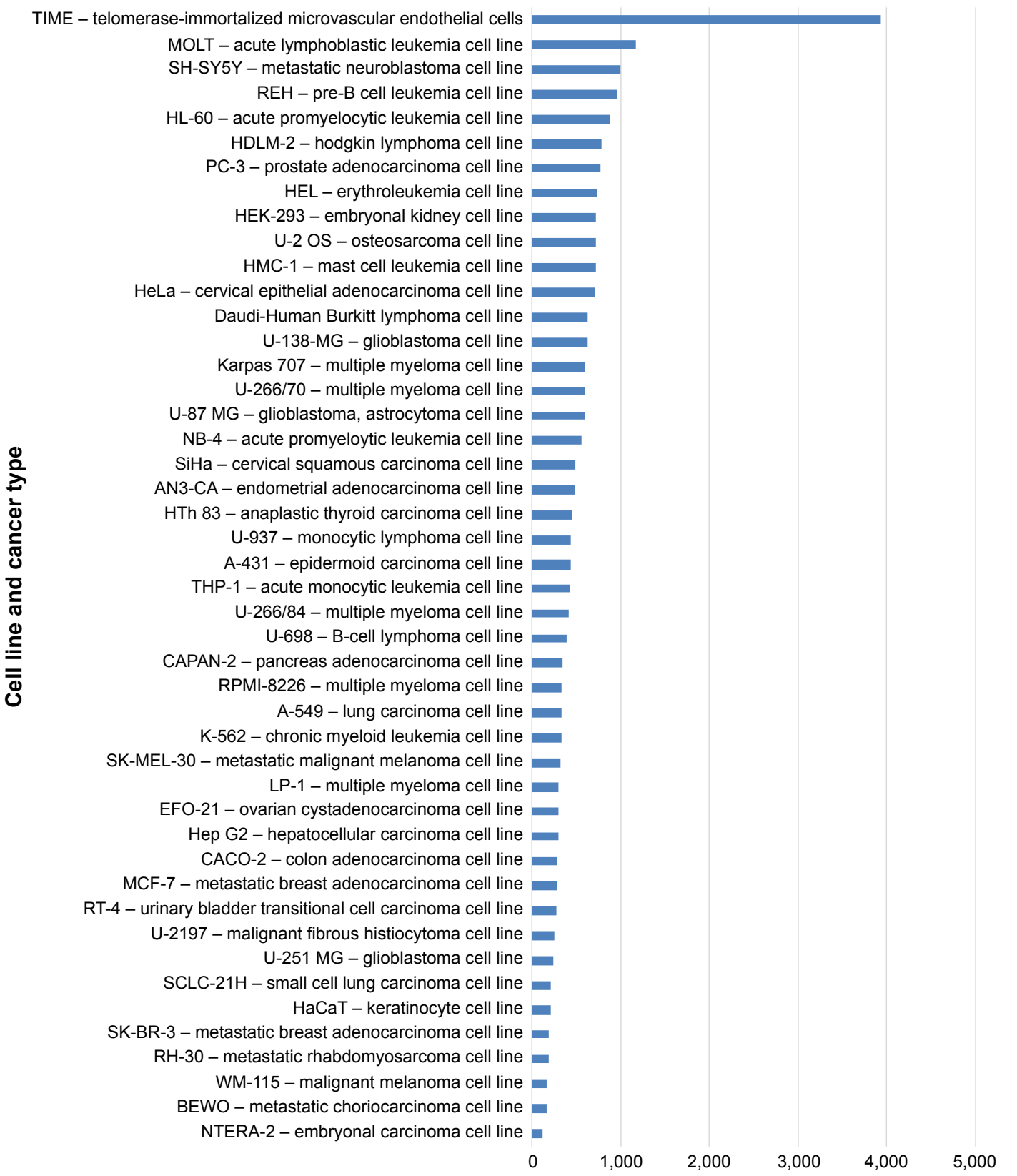

Figure 3 ELTDI protein levels in human cancer cell lines. The results show the intensity of antibody staining (protein levels) for each cell line. Results were obtained from the Human Protein Atlas Database (http://www.proteinatlas.org/ENSG000001626I8-ELTDI/cell/HPA025229, accessed October 17, 2015). ${ }^{77}$

Abbreviation: ELTDI, epidermal growth factor, latrophilin, and seven transmembrane domain-containing protein I on chromosome I.

cells showed higher ELTD1 staining when compared with endothelial cells. Increased ELTD1 staining was also correlated with higher microvascular density levels and reduced hypoxia signature in some forms of cancer/tumor. ${ }^{19}$ The article also points out that ELTD1 impairment in endothelial cells halved the tumor cells' capacity to sprout new microvessels. Furthermore, Masiero et al demonstrated, using both in vivo and in vitro models, that the two main antagonistic pathways involved in angiogenesis (VEGF/bFGF and DLL4-
Notch) ${ }^{60-62}$ had an opposing effect on ELTD1 levels (the former increased ELTD1 expression while the latter determined the exact opposite $)^{19}$ (Figure 1). A study by Dieterich et al ${ }^{76}$ also demonstrated that in human glioblastomas, increased VEGF-A signaling produced higher levels of ELTD1 gene expression in endothelial cells. Perhaps with a better understanding of the processes behind how ELTD1 works, which are currently unknown, such as ligand-receptor interaction and signaling pathways or the effect mutations have on the 


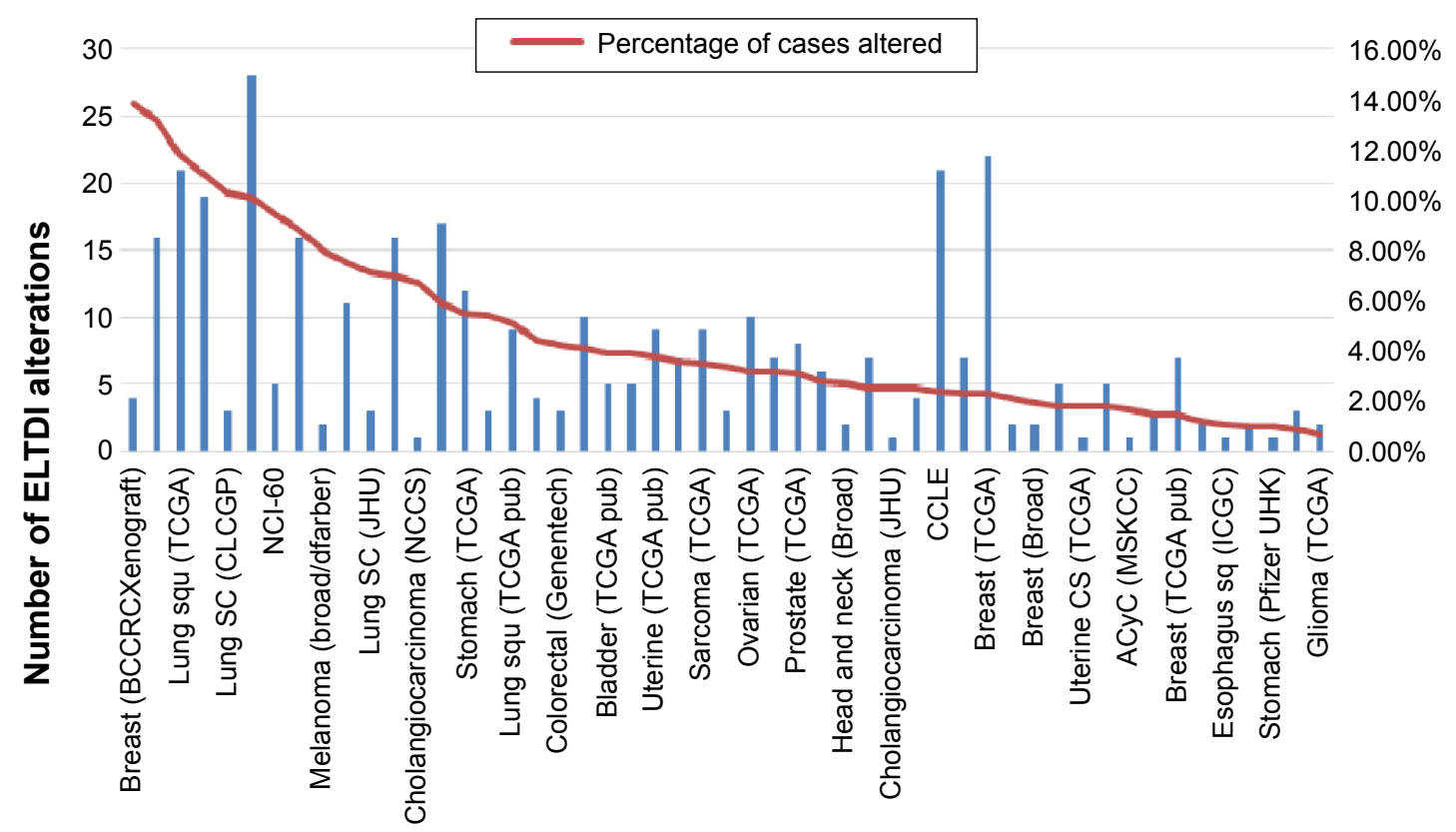

\section{Cancer type and study}

Figure 4 ELTDI genetic alterations (mutations, amplifications, and deletions) in different human tumor samples. Results are shown as the number of alterations and percentage of alterations per samples analyzed in each individual study and only shows cancer types where genetic alterations are present. The results were obtained from the BioPortal for Cancer Genomics database (http://bit.ly/IPyuYcR, accessed October 17, 20I5). ${ }^{78}$

Abbreviations: ELTDI, epidermal growth factor, latrophilin, and seven transmembrane domain-containing protein I on chromosome I; lung SC, lung squamous cells.

receptor function, we may draw a parallel between ELTD1 and the well-studied VEGF and in terms of involvement in both normal and neoplastic angiogenesis. However, because of the scarcity of information regarding ELTD1 due to the relatively recent discovery of the receptor, further studies are required to confirm its involvement in these mechanisms.

\section{Conclusion}

Recent studies have linked ELTD1 levels to both normal and pathological angiogenesis, such as cardiac hypertrophy in mice and even the development of nouvelle microvessels in various cancer types. One association that stands out is the link between ELTD1 and the evolution of GBM, recently pointed out in various studies. If proven feasible, this association may provide not only a viable biomarker for this highly aggressive cancer, but also a target for future therapeutic agents. These therapeutic approaches should focus on either silencing the ELTD1 gene using methods such as small interfering RNA or blocking the receptor with antibodies. However, with little knowledge about the ligands binding to the receptor or the pathways involved in downstream signal transduction, targeting ELTD1 might still prove problematic.

With several other roles besides vascular proliferation in cancer such as graft-versus-host disease, cannabis addiction, obesity or adaption to altitude in certain populations and notably the presence in a large number of normal tissues, ELTD1 may play a larger role than expected in the human body. Hopefully, increased attention to this receptor may shed some light on its multiple functions leading to a better understanding on how some pathological mechanisms are interrelated and how they can be tackled.

\section{Acknowledgment}

The paper was financed by "Program of Excellence in multidisciplinary doctoral and postdoctoral research in chronic diseases", Contract No POSDRU/159/1.5/S/133377, cofinanced project from the European Social Fund by Operational Sectoral Programme Human Resources Development 2007-2013 and Executive Agency for Higher Education, Research, Development and Innovation Funding Romania, Grant PN-II-ID-PCE-2011-3-1041, Romania.

\section{Author contributions}

All authors contributed toward the literature search, data analysis, drafting and critically revising the paper and agree to be accountable for all aspects of the work.

\section{Disclosure}

The authors report no conflicts of interest in this work. 


\section{References}

1. Wallgard E, Larsson E, He L, et al. Identification of a core set of 58 gene transcripts with broad and specific expression in the microvasculature. Arterioscler Thromb Vasc Biol. 2008;28(8):1469-1476.

2. van Beijnum JR, Nowak-Sliwinska P, Huijbers EJ, Thijssen VL, Griffioen AW. The great escape; the hallmarks of resistance to antiangiogenic therapy. Pharmacol Rev. 2015;67(2):441-461.

3. McIntyre A, Harris AL. Metabolic and hypoxic adaptation to antiangiogenic therapy: a target for induced essentiality. EMBO Mol Med. 2015;7(4):368-379.

4. Rapisarda A, Melillo G. Overcoming disappointing results with antiangiogenic therapy by targeting hypoxia. Nat Rev Clin Oncol. 2012; 9(7):378-390.

5. Glade Bender J, Cooney EM, Kandel JJ, Yamashiro DJ. Vascular remodeling and clinical resistance to antiangiogenic cancer therapy. Drug Resist Updat. 2004;7(4-5):289-300.

6. Bergers G, Hanahan D. Modes of resistance to anti-angiogenic therapy. Nat Rev Cancer. 2008;8(8):592-603.

7. Field KM, Jordan JT, Wen PY, Rosenthal MA, Reardon DA. Bevacizumab and glioblastoma: scientific review, newly reported updates, and ongoing controversies. Cancer. 2015;121(7):997-1007.

8. Haaland B, Chopra A, Acharyya S, Fay AP, Lopes Gde L. Comparative effectiveness of approved first-line anti-angiogenic and molecularly targeted therapeutic agents in the treatment of good and intermediate risk metastatic clear cell renal cell carcinoma. BMC Cancer. 2014;14:592.

9. Pradeep CR, Sunila ES, Kuttan G. Expression of vascular endothelial growth factor (VEGF) and VEGF receptors in tumor angiogenesis and malignancies. Integr Cancer Ther. 2005;4(4):315-321.

10. Byrne AM, Bouchier-Hayes DJ, Harmey JH. Angiogenic and cell survival functions of vascular endothelial growth factor (VEGF). $J$ Cell Med. 2005;9(4):777-794.

11. Tandle A, Libutti SK. Antiangiogenic therapy: targeting vascular endothelial growth factor and its receptors. Clin Adv Hematol Oncol. 2003;1(1):41-48.

12. Fontanella C, Ongaro E, Bolzonello S, Guardascione M, Fasola G, Aprile G. Clinical advances in the development of novel VEGFR2 inhibitors. Ann Transl Med. 2014;2(12):123.

13. Aprile G, Rijavec E, Fontanella C, Rihawi K, Grossi F. Ramucirumab: preclinical research and clinical development. Onco Targets Therapy. 2014;7:1997-2006.

14. Sharma T, Dhingra R, Singh S, et al. Aflibercept: a novel VEGF targeted agent to explore the future perspectives of anti-angiogenic therapy for the treatment of multiple tumors. Mini Rev Med Chem. 2013;13(4): $530-540$

15. Zhao Y, Adjei AA. Targeting angiogenesis in cancer therapy: moving beyond vascular endothelial growth factor. Oncologist. 2015;20 660-673.

16. Alessi P, Leali D, Camozzi M, Cantelmo A, Albini A, Presta M. AntiFGF2 approaches as a strategy to compensate resistance to anti-VEGF therapy: long-pentraxin 3 as a novel antiangiogenic FGF2-antagonist. Eur Cytokine Netw. 2009;20(4):225-234.

17. Medinger M, Passweg J. Angiogenesis in myeloproliferative neoplasms, new markers and future directions. Memo. 2014;7:206-210.

18. Secord AA, Nixon AB, Hurwitz HI. The search for biomarkers to direct antiangiogenic treatment in epithelial ovarian cancer. Gynecol Oncol. 2014;135(2):349-358.

19. Masiero M, Simoes FC, Han HD, et al. A core human primary tumor angiogenesis signature identifies the endothelial orphan receptor ELTD1 as a key regulator of angiogenesis. Cancer cell. 2013;24(2): 229-241.

20. Favara DM, Banham AH, Harris AL. A review of ELTD1, a pro-angiogenic adhesion GPCR. Biochem Soc Trans. 2014;42(6):1658-1664.

21. Harkensee C, Oka A, Onizuka M, et al. Microsatellite scanning of the immunogenome associates MAPK14 and ELTD1 with graft-versus-host disease in hematopoietic stem cell transplantation. Immunogenetics. 2013;65(6):417-427.
22. Pekow J, Dougherty U, Huang Y, et al. Gene signature distinguishes patients with chronic ulcerative colitis harboring remote neoplastic lesions. Inflamm Bowel Dis. 2013;19(3):461-470.

23. Eichstaedt CA, Antao T, Pagani L, Cardona A, Kivisild T, Mormina M. The Andean adaptive toolkit to counteract high altitude maladaptation: genome-wide and phenotypic analysis of the Collas. PLoS One. 2014;9(3):e93314.

24. Agrawal A, Pergadia ML, Saccone SF, et al. An autosomal linkage scan for cannabis use disorders in the nicotine addiction genetics project. Arch Gen Psychiatry. 2008;65(6):713-721.

25. Lee KT, Byun MJ, Kang KS, et al. Neuronal genes for subcutaneous fat thickness in human and pig are identified by local genomic sequencing and combined SNP association study. PLoS One. 2011;6(2):e16356.

26. Porto Neto LR, Bunch RJ, Harrison BE, Barendse W. DNA variation in the gene ELTD1 is associated with tick burden in cattle. Anim Genet. 2011;42(1):50-55.

27. Nechiporuk T, Urness LD, Keating MT. ETL, a novel seven-transmembrane receptor that is developmentally regulated in the heart. ETL is a member of the secretin family and belongs to the epidermal growth factor-seventransmembrane subfamily. J Biol Chem. 2001;276(6):4150-4157.

28. Nicolaidis S. Biomarkers of glioblastoma multiforme. Metabolism. 2015;64(3 Suppl 1):S22-S27.

29. Towner RA, Jensen RL, Colman H, et al. ELTD1, a potential new biomarker for gliomas. Neurosurgery. 2013;72(1):77-90.

30. Eo HS, Choi JP, Noh SJ, Hur CG, Kim W. A combined approach for the classification of $\mathrm{G}$ protein-coupled receptors and its application to detect GPCR splice variants. Comput Biol Chem. 2007;31(4):246-256.

31. Baldwin JM. Structure and function of receptors coupled to $G$ proteins. Curr Opin Cell Biol. 1994;6(2):180-190.

32. Lefkowitz RJ. The superfamily of heptahelical receptors. Nat Cell Biol. 2000;2(7):E133-E136.

33. Schioth HB, Fredriksson R. The GRAFS classification system of G-protein coupled receptors in comparative perspective. Gen Comp Endocrinol. 2005;142(1-2):94-101.

34. Formstone CJ. 7TM-Cadherins: developmental roles and future challenges. Adv Exp Med Biol. 2010;706:14-36.

35. Kaur B, Brat DJ, Devi NS, Van Meir EG. Vasculostatin, a proteolytic fragment of brain angiogenesis inhibitor 1, is an antiangiogenic and antitumorigenic factor. Oncogene. 2005;24(22):3632-3642.

36. Shiratsuchi $T$, Nishimori $H$, Ichise $H$, Nakamura $Y$, Tokino T. Cloning and characterization of BAI2 and BAI3, novel genes homologous to brain-specific angiogenesis inhibitor 1 (BAI1). Cytogenet Cell Genet. 1997;79(1-2):103-108.

37. Pickering C, Hagglund M, Szmydynger-Chodobska J, et al. The Adhesion GPCR GPR 125 is specifically expressed in the choroid plexus and is upregulated following brain injury. BMC Neurosci. 2008;9:97.

38. Kwakkenbos MJ, Kop EN, Stacey M, et al. The EGF-TM7 family: a postgenomic view. Immunogenetics. 2004;55(10):655-666.

39. Hamann J, Koning N, Pouwels W, et al. EMR1, the human homolog of F4/80, is an eosinophil-specific receptor. Eur J Immunol. 2007;37(10): 2797-2802.

40. Oda K, Shiratsuchi T, Nishimori H, et al. Identification of BAIAP2 (BAI-associated protein 2), a novel human homologue of hamster IRSp53, whose SH3 domain interacts with the cytoplasmic domain of BAI1. Cytogenet Cell Genet. 1999;84(1-2):75-82.

41. Gao FB, Brenman JE, Jan LY, Jan YN. Genes regulating dendritic outgrowth, branching, and routing in Drosophila. Genes Dev. 1999;13(19): 2549-2561.

42. Usui T, Shima Y, Shimada Y, et al. Flamingo, a seven-pass transmembrane cadherin, regulates planar cell polarity under the control of Frizzled. Cell. 1999;98(5):585-595.

43. Li W, Gao FB. Actin filament-stabilizing protein tropomyosin regulates the size of dendritic fields. J Neurosci. 2003;23(15):6171-6175.

44. Seifert JR, Mlodzik M. Frizzled/PCP signalling: a conserved mechanism regulating cell polarity and directed motility. Nat Rev Genet. 2007;8(2):126-138. 
45. Devenport D, Oristian D, Heller E, Fuchs E. Mitotic internalization of planar cell polarity proteins preserves tissue polarity. Nat Cell Biol. 2011;13(8):893-902.

46. Fredriksson R, Lagerstrom MC, Lundin LG, Schioth HB. The G-proteincoupled receptors in the human genome form five main families. Phylogenetic analysis, paralogon groups, and fingerprints. Mol Pharmacol. 2003;63(6):1256-1272.

47. Koirala S, Jin Z, Piao X, Corfas G. GPR56-regulated granule cell adhesion is essential for rostral cerebellar development. J Neurosci. 2009;29(23):7439-7449.

48. Yona $\mathrm{S}$, Lin HH, Dri P, et al. Ligation of the adhesion-GPCR EMR2 regulates human neutrophil function. FASEB J. 2008;22(3):741-751.

49. Koh JT, Kook H, Kee HJ, et al. Extracellular fragment of brain-specific angiogenesis inhibitor 1 suppresses endothelial cell proliferation by blocking alphavbeta5 integrin. Exp Cell Res. 2004;294(1):172-184.

50. Cork SM, Kaur B, Devi NS, et al. A proprotein convertase/MMP-14 proteolytic cascade releases a novel $40 \mathrm{kDa}$ vasculostatin from tumor suppressor BAI1. Oncogene. 2012;31(50):5144-5152.

51. Capasso M, Durrant LG, Stacey M, Gordon S, Ramage J, Spendlove I. Costimulation via CD55 on human CD4+ T cells mediated by CD97. J Immunol. 2006;177(2):1070-1077.

52. Huang YS, Chiang NY, Hu CH, et al. Activation of myeloid cell-specific adhesion class $\mathrm{G}$ protein-coupled receptor EMR2 via ligation-induced translocation and interaction of receptor subunits in lipid raft microdomains. Mol Cell Biol. 2012;32(8):1408-1420.

53. Leemans JC, te Velde AA, Florquin S, et al. The epidermal growth factor-seven transmembrane (EGF-TM7) receptor CD97 is required for neutrophil migration and host defense. J Immunol. 2004;172(2): 1125-1131

54. Cullen M, Elzarrad MK, Seaman S, et al. GPR124, an orphan G proteincoupled receptor, is required for CNS-specific vascularization and establishment of the blood-brain barrier. Proc Nati Acad Sci U S A. 2011;108(14):5759-5764.

55. Anderson KD, Pan L, Yang XM, et al. Angiogenic sprouting into neural tissue requires Gpr124, an orphan $\mathrm{G}$ protein-coupled receptor. Proc Nati Acad Sci U S A. 2011;108(7):2807-2812.

56. Wang T, Ward Y, Tian L, et al. CD97, an adhesion receptor on inflammatory cells, stimulates angiogenesis through binding integrin counterreceptors on endothelial cells. Blood. 2005;105(7):2836-2844.

57. Kuhnert F, Mancuso MR, Shamloo A, et al. Essential regulation of CNS angiogenesis by the orphan G protein-coupled receptor GPR124. Science. 2010;330(6006):985-989.

58. Bjarnadottir TK, Fredriksson R, Hoglund PJ, Gloriam DE, Lagerstrom MC, Schioth HB. The human and mouse repertoire of the adhesion family of G-protein-coupled receptors. Genomics. 2004;84(1): 23-33.

59. Flicek P, Amode MR, Barrell D, et al. Ensembl 2014. Nucleic Acids Research. 2014;42(Database issue):D749-D755.

60. Li JL, Harris AL. Crosstalk of VEGF and Notch pathways in tumour angiogenesis: therapeutic implications. Front Biosci. 2009;14: 3094-3110

61. Thurston G, Kitajewski J. VEGF and Delta-Notch: interacting signalling pathways in tumour angiogenesis. Br J Cancer. 2008;99(8): 1204-1209
62. Hellstrom M, Phng LK, Gerhardt H. VEGF and Notch signaling: the yin and yang of angiogenic sprouting. Cell Adh Migr. 2007;1(3): 133-136.

63. Xiao J, Jiang H, Zhang R, et al. Augmented cardiac hypertrophy in response to pressure overload in mice lacking ELTD1. PLoS One. 2012; 7(5):e35779.

64. Wu C, Orozco C, Boyer J, et al. BioGPS: an extensible and customizable portal for querying and organizing gene annotation resources. Genome Biol. 2009;10(11):R130.

65. Grossman SA, Batara JF. Current management of glioblastoma multiforme. Semin Oncol. 2004;31(5):635-644.

66. Krex D, Klink B, Hartmann C, et al. Long-term survival with glioblastoma multiforme. Brain. 2007;130(Pt 10):2596-2606.

67. Stupp R, Hegi ME, Mason WP, et al. Effects of radiotherapy with concomitant and adjuvant temozolomide versus radiotherapy alone on survival in glioblastoma in a randomised phase III study: 5 -year analysis of the EORTC-NCIC trial. Lancet Oncol. 2009;10(5):459-466.

68. Sangar V, Funk CC, Kusebauch U, Campbell DS, Moritz RL, Price ND. Quantitative proteomic analysis reveals effects of epidermal growth factor receptor (EGFR) on invasion-promoting proteins secreted by glioblastoma cells. Mol Cell Proteomics. 2014;13(10):2618-2631.

69. Gan HK, Cvrljevic AN, Johns TG. The epidermal growth factor receptor variant III (EGFRvIII): where wild things are altered. FEBS J. 2013;280(21):5350-5370

70. Crespo I, Vital AL, Gonzalez-Tablas M, et al. Molecular and Genomic Alterations in Glioblastoma Multiforme. Am J Pathol. 2015;185(7): 1820-1833.

71. Stieber D, Abdul Rahim SA, Niclou SP. Novel ways to target brain tumour metabolism. Expert Opin Ther Targets. 2011;15(10):1227-1239.

72. Sonoda Y, Yokosawa M, Saito R, et al. O(6)-Methylguanine DNA methyltransferase determined by promoter hypermethylation and immunohistochemical expression is correlated with progression-free survival in patients with glioblastoma. Int J Clin Oncol. 2010;15(4): 352-358.

73. Phillips HS, Kharbanda S, Chen R, et al. Molecular subclasses of high-grade glioma predict prognosis, delineate a pattern of disease progression, and resemble stages in neurogenesis. Cancer Cell. 2006;9(3):157-173.

74. Cohen AL, Colman H. Glioma biology and molecular markers. Cancer Treat Res. 2015;163:15-30.

75. Mahmoudi K, Ezrin A, Hadjipanayis C. Small extracellular vesicles as tumor biomarkers for glioblastoma. Mol Aspects Med. 2015;45: 97-102.

76. Dieterich LC, Mellberg S, Langenkamp E, et al. Transcriptional profiling of human glioblastoma vessels indicates a key role of VEGF-A and TGFbeta2 in vascular abnormalization. J Pathol. 2012;228(3): 378-390.

77. Uhlen M, Oksvold P, Fagerberg L, et al. Towards a knowledge-based Human Protein Atlas. Nat Biotechnol. 2010;28(12):1248-1250.

78. Cerami E, Gao J, Dogrusoz U, et al. The cBio cancer genomics portal: an open platform for exploring multidimensional cancer genomics data. Cancer Discov. 2012;2(5):401-404.
OncoTargets and Therapy

\section{Publish your work in this journal}

OncoTargets and Therapy is an international, peer-reviewed, open access journal focusing on the pathological basis of all cancers, potential targets for therapy and treatment protocols employed to improve the management of cancer patients. The journal also focuses on the impact of management programs and new therapeutic agents and protocols on
Dovepress

patient perspectives such as quality of life, adherence and satisfaction The manuscript management system is completely online and includes a very quick and fair peer-review system, which is all easy to use. Visit http://www.dovepress.com/testimonials.php to read real quotes from published authors. 